https://doi.org/10.21670/ref.2115078

Artículos

\title{
Dimensiones de género ante el COVID-19: narrativas de mujeres transfronterizas en el contexto Mexicali-Caléxico
}

\section{Gender dimensions of Covid-19: transborder women's narratives in the Mexicali-Calexico case}

Recibido el 30 de noviembre de 2020. Aceptado el 24 de septiembre de 2021. Publicado el 30 de septiembre de 2021.

*Autora para correspondencia: Magdalena Villarreal. Correo electrónico: mvillarreal@ciesas.edu.mx
Esta obra está protegida bajo una Licencia Creative Commons Atribución-NoComercial 4.0 Internacional. Magdalena Villarreal Martínez ${ }^{a^{*}}$ (iD https://orcid.org/0000-0002-5644-1126
Lya Margarita Niño Contreras $^{\mathrm{b}}$ (iD) https://orcid.org/0000-0003-4670-7194

\footnotetext{
${ }^{a}$ Centro de Investigación y Estudios Superiores en Antropología Social, Occidente, Guadalajara, México, correo electrónico: mvillarreal@ciesas.edu.mx

b Universidad Autónoma de Baja California, Instituto de Investigaciones Sociales, Mexicali, México, correo electrónico: lnino@uabc.edu.mx
}

\section{Resumen}

La pandemia ha tenido implicaciones a distintos niveles. Aquí se muestra el impacto en mujeres transfronterizas que vieron afectada su vida laboral, la lucha por sus derechos y sus labores como cuidadoras. Se subraya la intrínseca articulación entre las relaciones económicas y sociales de pobladores de ambos lados de la frontera, las dimensiones de género que afectan a las mujeres en contextos transfronterizos y la diferenciación social que se genera entre quienes poseen un tipo de documento u otro a partir del cierre parcial de la frontera. El análisis se basa en casos etnográficos (2019-2020) elegidos entre una muestra más amplia para dar cuenta de una gama de mujeres que han logrado avances en su proceso de autonomía y empoderamiento, pero se ven vulneradas ante el cierre de la frontera.

Palabras clave: COVID-19, cierre de frontera, mujeres transfronterizas, desigualdad de género.

\section{Abstract}

The pandemic has had implications at different levels. This article shows the impact on transborder women whose working lives have been affected, as has their struggle for their rights and their labor as care-workers. We underline the intrinsic articulation between economic and social relations of inhabitants on both sides of the international border, gender dimensions that affect trans-frontier women and the social differentiation that is generated between those that hold one type of document or another on view of the partial closure of the borderline. We base our analysis on ethnographic cases chosen a broader sampler (2019-2020) to

CÓMO CITAR: Villarreal Martínez, M. \& Niño Contreras, L. M. (2021). Dimensiones de género ante el COVID-19: narrativas de mujeres transfronterizas en el contexto Mexicali-Caléxico [Gender dimensions of Covid-19: transborder women's narratives in the Mexicali-Calexico case] Estudios Fronterizos, 22, e078. https://doi.org/10.21670/ref.2115078 
account for a gamut of women who have made strides in their processes of autonomy and empowerment, but find themselves made vulnerable by the closure of the borderline.

Keywords: COVID-19, closure of the borderline, transborder women, gender inequalities.

\section{Introducción}

La pandemia ha trastocado las agendas cotidianas de miles de personas en el mundo. Cada región geográfica se ha visto afectada de manera particular, pero el planeta entero se conmociona, se paraliza, se conmueve, se confunde, para después naturalizar la situación pandémica, y diseña sus particulares estrategias para manejarla.

Este es el escenario en la frontera norte de México, aunque tiene características distintivas. La pandemia ha azotado con olas de diversa magnitud. La región se estremece ante los contagios, el sufrimiento y los decesos ${ }^{1}$ y tiende a comprender el fenómeno con la imputación de responsabilidad "al otro".

Se habla, por un lado, de la presencia de europeos que pudieron haber sido portadores del virus en las plantas maquiladoras, donde conviven miles de trabajadores bajo un mismo techo. El cruce cotidiano de personas entre un país y otro, la frenética actividad comercial, trabajadores mexicanos que van a laborar a los campos agrícolas del Valle Imperial, estudiantes transfronterizos, jóvenes del lado estadounidense que pasan a México para visitar centros nocturnos, población norteamericana que viaja a Mexicali para atenderse en cuestiones de salud, etcétera. Al otro lado de la frontera, "el otro" es el mexicano y quienes cruzan la frontera México-Estados Unidos. Por ello, había que cerrar la frontera. Y eso fue lo que se hizo. Lo que ha afectado a miles de personas que cruzaban cotidianamente para trabajar, para realizar trámites, para cuidar enfermos. Las mujeres, en su calidad de madres, esposas, cuidadoras, trabajadoras y luchadoras sociales fueron doblemente victimizadas: por la pandemia y por el cierre de la frontera.

En las líneas que siguen se presenta este escenario, donde se muestran las estrategias truncadas de distintas mujeres que se ven afectadas por la pandemia y por el cierre parcial de la frontera. Y es que una crisis de esta magnitud pone en evidencia una abundancia de procesos a los que se presta poca atención en la apresurada cotidianeidad. Uno de ellos es el impacto de la pandemia en las mujeres. Se habla aquí de perspectiva de género porque es por su identidad de género que ellas asumen ciertos roles y que ciertos roles les son impuestos. Se señala la manera en que la pandemia y las restricciones fronterizas impactan a mujeres que tienen una condición transfronteriza. Esta dimensión es enfatizada también en un documento de las Naciones Unidas, elaborado tras las epidemias del sida, el Ébola y el Zika1, con el fin de fortalecer los sistemas nacionales e internacionales de prevención y respuesta eficaz a futuras crisis de salud. Se trata de un informe que recomienda enfáticamente el centrar la atención en las dimensiones de género de las crisis de salud globales (Ruíz, 2021). El estudio

\footnotetext{
${ }^{1}$ México suma 234969 decesos por COVID-19. México se mantiene como el cuarto país del mundo con más muertes por COVID-19, detrás de Estados Unidos, Brasil y la India (Forbes Staff, 2021). Los decesos por COVID-19 al 9 de agosto de 2020 registrados en Mexicali son de 1339 y de 244 para el Valle Imperial (Lara-Valencia \& García-Pérez, 2021).
} 
realizado por el rastreador COVID-19 Global Gender Response Tracker (2020) señala que de no ser tomadas en cuenta las dimensiones de género en la prevención de las pandemias se pudiera ocasionar un retroceso en la lucha por la equidad de género. El estudio está basado en tres ejes con enfoque de género que son: el combate a la violencia de género, el apoyo a los cuidados no remunerados y el fortalecimiento de la seguridad económica de las mujeres. Los resultados arrojan que "solo uno de cada ocho países ha implementado medidas para proteger a las mujeres y a las niñas de los impactos sociales y económicos de la pandemia" (Mujeres, género, violencia, pandemia y políticas públicas, 2020).

Con respecto al apoyo a los cuidados no remunerados, en el mencionado estudio se habla del papel que tiene la mujer en el cuidado de los otros, al mismo tiempo que debe mantener su rendimiento laboral. Se advierte que esto llevaría a las mujeres a renunciar a su trabajo o a un descenso en su productividad (COVID-19 Global Gender Response Tracker, 2020). Las mujeres dedican a los cuidados el triple de horas que los hombres. En el momento en el que se intensifican las tareas de cuidados existe el riesgo de que las jóvenes que estudian o trabajan, lo abandonen (Mass, en Alavez, 2020). Como bien lo mencionan Avendaño y colaboradores (2020)

(...) la literatura muestra otro tipo de afectación hacia las mujeres ante la presencia del COVID-19, que es la interrupción de los servicios de salud reproductiva y materna. La directora de la Organización Panamericana de la Salud (ops), Carissa F. Etienne, advirtió que la continua interrupción de los servicios de salud para las mujeres debido al COVID-19 podría borrar más de 20 años de avances en la reducción de la mortalidad materna y el aumento del acceso a la planificación familiar (...). (COVID-19 ocasiona impactos "devastadores" en las mujeres, afirma la directora de la oPs, 2021)

Este texto se enfoca en estas afectaciones. Pone la lente en que al ser una zona fronteriza se interrumpen circuitos y se añaden problemáticas relevantes para la vida de la población fronteriza. En la primera parte del texto se habla de estos circuitos, y en la segunda sobre el caso de las mujeres ante la pandemia. El análisis se basa en las narrativas de mujeres que viven y padecen estas realidades. El interés es resaltar de manera particular las formas creativas en que la gente encuentra soluciones y las implicaciones que esto tiene.

Se toma el caso de la zona transfronteriza Mexicali-Caléxico, en donde se exhibe el entretejimiento de diversas actividades y flujos económicos en ambos lados de la frontera, que muestran que las dos economías nacionales son en mayor grado permeables y se compenetran en muchos sentidos. La frontera es una línea divisoria, pero, más que nada, es un eje de tránsito fecundo para quienes la cruzan cotidianamente. Las restricciones de cruce fronterizo a raíz de la pandemia tienen un impacto directo en estos procesos y en particular en las vidas de las mujeres que cuentan con visa de turista y se ven imposibilitadas de cruzar a Estados Unidos ante el cierre parcial de la frontera. 
El texto tiene como antecedente tres estudios ${ }^{2}$ mediante los cuales se explora la realidad de hombres y mujeres que cruzan la frontera en su día a día.

La base principal de este análisis es trabajo etnográfico, el cual, dadas las limitaciones por la pandemia, se realizó a través de distintos medios. En la medida de lo posible se visitó a las personas en sus espacios del hogar o de convivencia, aunque se realizaron muchas llamadas telefónicas y comunicaciones a través de chats, facetime, etcétera, además de una revisión sistemática de fuentes de información secundaria, así como la realización de entrevistas a profundidad. Los casos mencionados a continuación son de mujeres de entre 21 y 74 años de edad, una de las cuales solo cuenta con secundaria trunca, otra hizo estudios universitarios en Estados Unidos y otra cursa estudios superiores en Mexicali. Dos se dedican al trabajo doméstico remunerado, una trabaja en el campo en Estados Unidos, otra en una tienda departamental en ese mismo país, y una más se contrata para el cuidado de personas mayores, también en Estados Unidos. Cinco viven en Caléxico, California y tres en Mexicali, Baja California. De estas, solo dos cuentan con visa de turista al igual que una de las que vive en Caléxico. El resto de quienes viven en Estados Unidos son residentes o ciudadanas de ese país.

\section{La vida fronteriza}

La frontera México-Estados Unidos se ha caracterizado por su gran dinamismo. El puerto fronterizo Caléxico-Mexicali registró en 2020 cifras que superan los 2.5 millones de movimientos entre ambos lados de la frontera, mientras que previo a la contingencia sanitaria, se llegaban a realizar más de 3.7 millones de cruces de personas (Baja California: instauran sistema de reconocimiento facial en Garita de Caléxico. Autoridades norteamericanas instalaron tecnología de comparación biométrica y facial en el cruce con Mexicali, 2021).

Mexicali, Baja California, se encuentra en la frontera norte de México con Estados Unidos. Caléxico, su ciudad gemela en California, se localiza en el Valle Imperial, un gran desierto convertido en área agrícola gracias a la irrigación traída desde el Río Colorado, pero sobre todo, a la fuerza de trabajo proveniente principalmente de Mexicali, ciudad que cuenta con más de un millón de habitantes, casi seis veces más que el Valle Imperial. Algunos de estos trabajadores, así como aquellos involucrados en otras actividades económicas en el país del norte (meseros, cocineros, trabajadoras domésticas, cuidadores de ancianos, entre otras), buscan conseguir la residencia en ese país o adquirir la doble ciudadanía. En este estudio se pudo comprobar que no son pocas las familias en las que unos de sus miembros son ciudadanos estadounidenses y otros mexicanos. Un hermano puede ser ciudadano estadounidense, otro residente y

\footnotetext{
${ }^{2}$ Quoras, pesos y dólares: flujos de divisas y finanzas en el caso de mujeres transmigrantes de Mexicali-Caléxico y sus valles (Niño et al., 2012). Prácticas sociales de mujeres transfronterizas: el caso de Mexicali-Caléxico (Niño \& Villarreal, 2013a). Los dos anteriores realizados en el Instituto de Investigaciones Sociales de la Universidad Autónoma de Baja California; y el proyecto Juggling Currencies in Transborder Contexts (Villarreal et al., 2015). Este último se llevó a cabo bajo los auspicios del Instituto de Dinero, Tecnología e Inclusión Financiera de la Universidad de California en Irvine, que incluyó la aplicación de una encuesta, observación participante y entrevistas formales e informales a hombres y mujeres que viven en ambos lados de la frontera internacional o conmutan regularmente entre ambos países.
} 
otros indocumentados cuando entran a Estados Unidos. Y el estatus legal en Estados Unidos tiene un impacto importante en las estrategias económicas de los hogares. La segregación ocupacional ha sido una característica importante en el mercado laboral que está imponiéndose para los inmigrantes mexicanos. En los contextos rurales prevalecen empleos inestables y precarios. Un número significativo de trabajadores se emplean en el campo, en "las corridas", esto es que emigran o se insertan en otras áreas agrícolas debido a que la temporada de trabajo en el campo en el Valle Imperial es muy corta, por lo que se trasladan al valle de Coachella y al valle de San Joaquín en California, así como también acuden a Arizona y a Texas. Lo anterior con el fin de que tanto su ingreso como su cheque de desempleo sea lo más alto posible, sin embargo, la estrategia tiene un costo social muy alto. Se ha documentado la precariedad y hacinamiento de la vivienda como un factor de exposición al virus del COVID-19 en los campos agrícolas en California (Gomez, 2020).

Quienes son más conocedores de los entresijos del mercado laboral incluso pueden recibir compensación por desempleo en Estados Unidos durante ciertas estaciones del año, mientras ellos se recorren a trabajar más al norte, o hacia México en las "corridas". Una estrategia involucra la utilización de varios números de seguridad social (generalmente adquiridos de forma ilegal) para aparecer como desempleado en uno y trabajar con el otro.

Esto marca el tipo de relaciones sociales desiguales que se forjan en la frontera, donde un número significativo de personas - la mayoría mexicanas o mexicoestadounidenses - cruzan la frontera todos los días para trabajar. Otros cruzan para apoyar en el cuidado de niños y personas de la tercera edad (López, 1994, 2020; Villarreal \& Niño, 2016); destaca el cruce transfronterizo con fines laborales y residenciales (Ojeda, 1994); para realizar estudios (Meza, 1989; Rocha \& Orraca, 2018); para efectos de la reproducción social (Ojeda, 1994; Villarreal \& Niño, 2016; Vargas \& Coubès, 2017); sin embargo, de forma más reciente, autores como Orraca (2019) han identificado una disminución de la población transmigrante, fenómeno acompañado del cambio de residencia.

El punto central de la frontera es el hecho de que, si bien divide - al seguir a Campos y Odgers (2012) se puede hablar de cómo el que las realidades económicas sean diferenciadas generan valores importantes en un lado y otro-, también es un punto importante de interacción. Es así como la movilidad adquiere gran relevancia. Como lo dicen las autoras:

La frontera puede ser un puente, una pared, o ambos a la vez, dependiendo de la habilidad de la persona para cruzarlo. Estas características permiten que las regiones fronterizas desnuden las contradicciones entre los flujos y las barreras del mundo moderno: la movilidad fronteriza no se produjo por el debilitamiento de las fronteras, sino a pesar de su reforzamiento (...) la habilidad de "ser móvil" es un recurso crítico en las regiones fronterizas (...). (Campos \& Odgers, 2012)

En este contexto, diversas prácticas, culturas y normatividades, con frecuencia concebidas como desintegradas, se entretejen y generan relaciones de diferenciación social y de poder. Aunque dicho poder no está en posesión absoluta de agentes aduanales o gubernamentales en Estados Unidos, estos ejercen un grado importante de control, el cual se deja ver de forma más clara en el marco de las restricciones en torno a la pandemia. 
Sin embargo, los actores involucrados logran generar ciertos espacios de maniobra. Encuentran resquicios donde pueden obtener algún beneficio para seguir operando los distintos procesos transfronterizos. En ocasiones esto proporciona un provecho a corto plazo, pero favorece la continuación de la desigualdad y reproducción de las relaciones de poder.

\section{El cierre parcial de la frontera y su impacto en las mujeres}

En marzo de 2020, Estados Unidos decretó el cierre parcial de su frontera con México, periodo que hasta septiembre de 2021 se ha extendido cada mes. De esta forma limitó el cruce fronterizo terrestre a actividades esenciales que son las médicas, las escolares y las de trabajo para sus connacionales o para quienes cuentan con una visa permanente de residencia y de trabajo y lo prohibió para quienes cuentan con visa de turista B2. Sin embargo, históricamente, y a pesar de necesitarse un documento legal para desempeñar un trabajo en Estados Unidos, cientos de personas solían cruzar diariamente la frontera con visa de turista y laborar en actividades como la construcción, hotelería, restaurantes, negocios, servicios de jardinería, de limpieza de casas, de cuidados a menores y personas de la tercera edad o con alguna enfermedad o discapacidad, o en el campo, entre otros.

Los impactos que ha tenido el COVID-19 y las políticas de restricción en el cruce de la frontera internacional entre Estados Unidos y México no han sido menores entre quienes tienen un estilo de vida transfronterizo, ${ }^{3}$ en particular las mujeres que viven en Mexicali y solían cruzar constantemente a Caléxico con visa de turista, ya sea para trabajar, para dar seguimiento a procesos administrativos o jurídicos ante la Suprema Corte de Justicia de EUA y que se han visto afectadas ante tales restricciones.

Nora y Mayra cuentan con visa de turista y hasta antes de la pandemia solían cruzar a Caléxico cotidianamente para trabajar, la primera de ellas limpiaba casas y la segunda trabajaba en el "fil" (campo agrícola). Yadira no cuenta con visa, pero tiene un proceso administrativo ante las oficinas del seguro social en El Centro, California, debido al deceso del padre de sus dos hijas que tienen una condición especial y ha visto frenado su proceso porque no se considera esencial en los protocolos de la pandemia en Estados Unidos. Sin embargo, para ella y su familia, la culminación del trámite es de alta prioridad.

El trabajo doméstico como el que realiza Nora es una actividad transfronteriza histórica, muy socorrida por las amas de casa para ayudarse con el gasto diario o apoyar a la familia, así como por las estudiantes para solventar los gastos escolares. Un número significativo de las entrevistadas realizan o han realizado esta actividad, la cual es bien pagada en Estados Unidos. Los comprobantes de estudio de Nora fueron una pieza

\footnotetext{
${ }^{3}$ La política de EUA de diferenciación social aplicada en el cruce de su frontera ha sido muy criticada y considerada como poco efectiva. Incluso hay quienes señalan que más que tener una argumentación médica esta es de carácter político (Cierre de frontera México-EU por Covid-19, decisión política, no sanitaria: WSJ, 2020), y ha tenido diversos impactos en la frontera, uno de ellos son los excesivos tiempos de espera para cruzar la línea debido al recorte del personal en las garitas, así como la disminución de los carriles en los puertos fronterizos, incluso la disminución del horario de las garitas, con lo que el tiempo de espera para cruzar por la garita centro de Mexicali puede ser de hasta 8 horas (Registran hasta 8 horas de espera en Garita Centro, 2020).
} 
clave en el trámite de la visa de turista, y la visa ha sido un recurso importante para ella, ya que el trabajo doméstico que desempeña en el Valle Imperial viene a paliar el constreñimiento de la economía doméstica. Ella solía ir a Caléxico y al Valle Imperial a realizar trabajo doméstico de forma discreta en casa de amistades de la adolescencia. Las restricciones del paso a Estados Unidos con visa de turista le han impedido cruzar e intenta compensar esto con otras actividades no tan bien remuneradas en México que permiten un pequeño complemento al bajo salario de su marido.

Nora ya había intentado resolver su situación de distintas maneras, incluida la sugerencia a su tío político que se casara con ella, y la petición a una amiga de que la solicitara ante el Departamento de Ciudadanía e Inmigración de Estados Unidos (UScis, por sus siglas en inglés) como trabajadora doméstica, pero ninguna de sus iniciativas prosperó.

Yadira, por otro lado, tiene un expediente ante la Suprema Corte en Estados Unidos, el cual ha tenido que ser suspendido. El motivo de la audiencia ante esta instancia se debe a que el papá de su pequeño hijo era ciudadano estadounidense, recientemente perdió la vida en un accidente de trabajo. El joven padre de familia tenía un seguro de vida por el trabajo, pero la suegra de Yadira le está peleando el beneficio de la aseguradora en la Suprema Corte. Su suegra está desconociendo al niño como nieto y pide que el dinero del seguro sea para ella y su hijo menor de edad que aparece como dependiente económico de su hijo finado en la declaración de impuestos ante el Servicio de Impuestos Internos (Internal Revenue Service, IRs). Yadira tiene alrededor de tres años con un estilo de vida transfronterizo. Ella cursa estudios superiores en una escuela particular de Mexicali, a la vez que trabaja en el "fil" en Estados Unidos para sufragar los gastos de sus estudios y para apoyar a su familia. Generalmente en el "fil" se tiene trabajo de 35 a 45 horas semanales con un ingreso de 80 dólares al día cuando se tienen documentos y alrededor de 70 dólares cuando se trabaja con pasaporte. Entonces puede decirse que el salario medio que recibe una trabajadora al trasmigrar para laborar en estas actividades equivale a más de 15 veces un salario mínimo general mexicano (Sández et al., 2016).

Hasta antes de la pandemia durante la temporada alta, Yadira, generalmente, cruzaba a Caléxico los domingos temprano, trataba de llevar su bolsa lo más ligera posible, y sin nada que delatara su trabajo en el "fil" ante los agentes de uscis, de domingo a miércoles se quedaba a dormir en el Valle Imperial con sus parientes políticos pues solía trabajar de lunes a jueves en el "fil" en el Valle Imperial y el mismo jueves regresaba a Mexicali para asistir a la escuela y continuar con sus estudios, así era la rutina que ella se había hecho los últimos años.

Actualmente no puede cruzar a Estados Unidos debido a las restricciones impuestas a las visas de turistas. Esto le ha afectado mucho en términos financieros, pero también en su estado de ánimo porque al no poder cruzar perdió una cita ante la Suprema Corte de Justicia en Estados Unidos. En las últimas ocasiones que se tuvo comunicación con Yadira, estaba preocupada y desesperada ante los hechos.

La Corte Suprema anunció la suspensión de la presentación de argumentos orales debido al coronavirus desde el mes de marzo. La mayoría de sus integrantes tiene 65 años o más, y corren mayor riesgo de enfermarse gravemente. Aunque los argumentos orales quedan suspendidos sin una nueva fecha definida, algunos(as) jueces han realizado los careos vía telefónica, 
dijo el tribunal en un comunicado (Coronavirus: la Corte Suprema de EE.UU. suspendió sus actividades por primera vez en más de un siglo, 2020). ${ }^{4}$

Sin embargo la opción de los careos vía telefónica solo aplica para ciudadanos estadounidenses.

El caso de Mayra tiene que ver con una demanda de pensión para sus hijas con discapacidad en las oficinas del seguro social en Estados Unidos. Mayra se separó del papá de sus hijas, él es ciudadano estadounidense y no les brinda una pensión alimenticia, lo que obligó a Mayra a desempeñarse como trabajadora doméstica en Mexicali. Al poco tiempo se vio en la necesidad de dejar tal actividad para atender de mejor forma a sus hijas que tienen una condición especial: la enfermedad de la neurona motora, atrofia que afecta las neuronas (células nerviosas) del cerebro y médula espinal y provoca debilidad y atrofia muscular. En ese tiempo que dejó la actividad del trabajo doméstico se estuvo asesorando con un abogado que la ayudó a realizar la demanda jurídica por manutención contra el padre biológico de sus hijas en Estados Unidos.

Sin contar con una visa para cruzar a Estados Unidos, pero con el apoyo de un abogado, Mayra logró ganar la demanda de manutención para sus hijas hace unos años y se sintió con libertad financiera para dedicarle más tiempo, de atenderlas, asistirlas y llevarlas a sus terapias físicas, ya que como dice Mayra, atender a sus hijas es un trabajo de 365 días al año. Sin embargo, poco antes de la pandemia del COVID-19 falleció su exmarido y las oficinas del seguro social le suspendieron el cheque de manutención de sus hijas. Debido a que Mayra no puede cruzar a Estados Unidos, un abogado la está apoyando en este trámite. Sin embargo, o están cerradas las oficinas del seguro social, o el número de casos atendidos ha disminuido drásticamente. Al respecto citamos a Jaral, licenciado y activista del Valle Imperial:

Para evitar la propagación del virus se han cerrado oficinas de gobierno, embajadas y consulados estadounidenses, lo cual ha afectado a las personas que querían renovar sus visas de turista. La pandemia afecta también el cierre, por ejemplo, de la oficina del seguro social donde va mucha gente a pelear pensiones, como es el caso de esposos que fallecieron. Las mujeres no pueden cruzar para llevar ese trámite para que se les pague el beneficio de viudas, o las pensiones de los hijos a través del seguro social. (J. Jaral, comunicación personal, 9 de octubre de 2020)

Otro caso drástico es el de Juana, quien vive en Mexicali. Su familia es emigrada y vive en Estados Unidos, pero ella solo cuenta con visa de turista. Ella es la hija menor de la familia, nació cuando todos sus hermanos y hermanas se habían emigrado en paquete. Su padre fue el que hizo la petición ante el uscis. Ahora sus hermanos y hermanas tienen la residencia permanente, menos ella. Nos comparte que hay promesas por parte

Sobre la Suprema Corte de Justicia, la única otra vez que, en 85 años de antigüedad, estuvo cerrada para los argumentos fue en octubre de 2001, cuando se detectó ántrax en la sala de correo del tribunal. Eso llevó a los jueces a sostener los argumentos en el tribunal federal, a media milla de la Corte Suprema. En una semana y después de una limpieza a fondo, el tribunal reabrió. En 1918, cuando la corte todavía se reunía dentro del Capitolio, los argumentos se pospusieron por un mes debido a la pandemia de gripe española y en los primeros años de la nación, en agosto de 1793 y agosto de 1798, se hicieron ajustes debido a los brotes de fiebre amarilla, dijo el tribunal (Coronavirus: la Corte Suprema de EE.UU. suspendió sus actividades por primera vez en más de un siglo, 2020). 
de su familia de emigrarla una vez que se conviertan en ciudadanos estadounidenses. Mientras tanto, el hecho es que el padre de Juana enfermó gravemente y a raíz del cierre de frontera no ha podido ir a visitarlo. Nos dice que hasta antes de la pandemia lo visitaba semanalmente.

Un caso similar es el de Blanca, quien tiene más de 20 años de emigrada, pero vive en Mexicali. A ella la emigró su exesposo, más no a los hijos. Actualmente se encuentra postrada en cama, y sus hijos, quienes cuentan con visa, pero trabajan en Estados Unidos, no han podido venir a visitarla.

Estos casos nos muestran la intrínseca relación entre la población y las autoridades de un lado y otro de la frontera. No solo se trata de circuitos económicos, sino legales, de parentesco, de responsabilidad familiar. Estos trámites suelen ser llevados por mujeres que han logrado un grado de emancipación o incluso empoderamiento que les permite moverse en las oficinas y manejar con cierta eficiencia las múltiples actividades económicas, profesionales y de cuidado de su familia. El cierre de la frontera hace peligrar este frágil equilibrio, haciendo que en muchos casos regresen a depender de su expareja o de sus familias. Ello además de los problemas causados directamente por la pandemia, incluidos quienes tienen que cuidar de enfermos o quienes como madres asumen el rol de maestras y tutoras de sus hijos que solo llevan clases por vía digital. Las madres son quienes generalmente se ven obligadas a estar hasta seis horas a un lado de sus hijos cuando toman clases en línea y a verificar que el menor entiende las explicaciones y sigue las instrucciones. Si él o la maestra pide un material, ella tiene que asegurarse de que está asequible. Si encargan una tarea, se pone con el menor a asegurarse de que la haga. Innumerables madres de familia comentan lo difícil que resulta para ellas esta cuarta jornada. Sumado a lo anterior, deben cuidar a cada minuto que su hijo y o hija no se conecte a programas inconvenientes en internet en lugar de estar participando en clase.

En el contexto transfronterizo, esto se incrementa, pues algunos niños viven en Mexicali y cursan sus estudios en Estados Unidos y las madres deben asegurarse de que cuentan con el equipo, el software y los materiales necesarios. No pocas veces ellas cruzan la frontera para conseguir algunos de estos materiales o para devolverlos. Sus labores en tanto mujeres se intensifican. Esto en una ciudad en la que un porcentaje muy importante de la población trabaja o hace algún trámite al otro lado de la frontera, además de que muchas tienen a sus hijos estudiando al otro lado de la frontera.

\section{Dimensiones de género en la región transfronteriza ante la pandemia}

Como se mencionó, un número significativo de mujeres mexicanas se trasladan cotidianamente entre las ciudades hermanas de Mexicali y Caléxico, en busca de cotejar los medios de vida financieros con los sociales. Laboran en la limpieza de viviendas y oficinas o en el cuidado de nietos o mascotas; son costureras, empleadas en empresas agrícolas o del sector salud; anuncian las salidas de los autobuses o taxis con destino a casinos como el Golden Acorn que queda a poco más de 100 kilómetros de Caléxico o hasta los que se encuentran en Las Vegas que se localizan a poco más de 550 kilómetros desde este mismo punto, cuya parada se encuentra a escasas cuadras de la línea; o incluso el punto de reunión puede ser el restaurante de comida rápida 
localizado a escasos metros del cruce fronterizo. Otras mujeres son "raiteras", ofrecen viajes a diferentes puntos de la región, como Heber, Holtville, El Centro, Imperial, Coachella; otras viven allá, pero sus familiares están en México y su economía se enmarca en contextos sociales y culturales mexicanos. Otras más se trasladan en las corridas, al seguir algún cultivo en particular. Los esfuerzos de estas mujeres han significado aportes fundamentales en las economías familiares para importantes sectores de la población en ambos lados de la frontera.

Sin embargo, como ha enfatizado en otros textos Villarreal (2017) "las identidades de génerojuegan un papel importante en la demarcación de espacios y la conformación de formas de acceso". Muchas de estas mujeres deben realizar dobles y triples jornadas, por las cuales reciben una remuneración menor o nula. $\mathrm{Y}$ aunque su contribución monetaria sea igual o mayor que la del hombre, tiende a valorarse como menor. A esto se agrega que la angustia y zozobra se entremezclan con las prácticas económicas, desde el miedo, ya no solo a ser explotadas, situación que muchas mujeres aceptan con tal de acceder a un ingreso, sino a ser rechazadas o a ser acosadas. La lucha por aumentar y hacer rendir sus ingresos y recursos involucra muchas dimensiones de la vida diaria, dimensiones en las que se reproducen discursos y clasificaciones que de antemano marcan desigualdad y violencia.

Como si fuera poco, la mayoría de estas mujeres destinan la totalidad de sus ingresos a los demás miembros de la familia. Es escaso el recurso que dejan para sí mismas. Múltiples estudios sobre la economía familiar (Chant, 2003; Enríquez, 1998; Folbre, 1982; Gibson-Graham, 1996; Harris, 1981; Moore, 1988; Roldán, 1988; Villarreal, 2007) han mostrado la falta de homogeneidad en la distribución del ingreso y los recursos en el interior del hogar. Esta situación es muy frecuente entre quienes cruzan la frontera, en particular debido a que muchas mujeres son madres solteras.

$\mathrm{Y}$ es que las configuraciones familiares pueden tener formas diversas, incluso en términos de nacionalidad y ciudadanía. Esto no solo obedece a la organización en torno al empleo. No son pocos los padres que envían a los hijos a estudiar a Caléxico o a San Diego "para que aprendan inglés" y las familias deciden parir a los hijos en Estados Unidos para que adquieran la doble nacionalidad. Una familia puede habitar en dos viviendas (una en cada lado de la frontera), una de las cuales hospeda también a parientes. Sin embargo, se toma en cuenta que el tener un pariente no es garantía de apoyo. Los riesgos involucrados en este tipo de prácticas son conocidos. La gente aprende a vivir con miedos, con cierta incertidumbre de que sus modos de operación resultarán exitosos.

Los cálculos financieros que realizan las mujeres que cotidianamente cruzan la frontera para trabajar o realizar actividades económicas tienden a hacerse tanto en dólares como en pesos. En México se hace la conversión mental a dólares, y en Estados Unidos a pesos. Sin embargo, en general los cálculos se hacen con información un tanto parcial. Como en el caso de parir en Estados Unidos sin contar con seguro médico, lo cual es riesgoso y caro. También es crítico el acceso a información que carecen muchas mujeres para acercarse a trabajar a ciertos plantíos, por lo que se contratan en cultivos con mala paga y malas condiciones de trabajo. Por ejemplo, laborar en el cultivo de la lechuga no es considerado un buen trabajo: hay que esperar a que se quite el hielo, se paga a partir de que se entra al "fil" y se empieza a cortar (Niño \& Villarreal, 2013b). De igual manera, son más las mujeres que trabajan en el espárrago, el cual, como dicen ellas "es muy matado y luego muy mal pagado". Quienes logran acceder a otros 
cultivos con base en sus redes sociales o su habilidad para el trabajo pueden obtener un ingreso un poco más alto.

Pero la movilidad social tiene un costo alto, como se deja ver también en el caso de Nora, quien para estudiar debe contratarse como trabajadora doméstica en Estados Unidos. Pero esto implica hacer malabarismos entre atender a su hija, tener su hogar en orden con comida lista y limpieza adecuada, además de la pérdida de tiempo que implica cruzar la frontera. Otros cálculos a los que hay que tener acceso se relacionan con el reembolso de impuestos. En los procesos de cálculo pesan sobremanera elementos no financieros, como lo explica una mujer que ahora recibe la pensión de Estados Unidos. Lamenta que se perdió de muchas cosas con sus hijos porque trabajaba el "fil" y se iba a las corridas.

Por otro lado, las personas más vulnerables también se contratan con frecuencia en los servicios de proximidad, los cuales tienen una importante demanda. No es fortuito que en la sección de clasificados de los diarios mexicanos se soliciten personas con visa de turista para que trabajen en Caléxico o en el Valle Imperial para cuidar a personas mayores o a menores, estas actividades se realizan en condiciones sumamente precarias donde se trabaja hasta 12 horas diarias por 150 dólares a la semana (García \& Niño, 2011).

En suma, se puede decir que la diferenciación de género incide directamente en las opciones de empleo y remuneración. En el funcionamiento económico y financiero de los hogares las mujeres juegan papeles fundamentales. El ser mujer facilita ciertos caminos y obstruye otros.

Las mujeres transfronterizas combinan distintos tipos de inversión, ahorro y deuda, en dólares y en pesos, y se agencian distintos apoyos gubernamentales, tanto en México como en Estados Unidos. Pero las cuestiones financieras están íntimamente imbricadas en procesos sociales, culturales y legales. Es decir, los procesos económicos no existen en aislamiento. Así, sus estrategias económicas incluyen prácticas monetarias y nomonetarias para asegurar el futuro de sus hijos y su propia estabilidad. Dichas prácticas, formateadas en lenguajes culturales y normativos diversos, se combinan y entrecruzan al llevarse a cabo en países distintos (Villarreal \& Niño, 2016).

Se trata de una "cultura financiera" poco analizada, en la que entra en juego la medición de riesgos, así como categorías y diferenciaciones sociales. Para tomar decisiones, es necesario dar cuenta de factores sociales, económicos y culturales, en los cuales la identidad de género juega un papel fundamental. Sin embargo, hay un grado de espacio de maniobra en el cual pueden recurrir a un sistema normativo, financiero y social para subsanar los déficits en otro. Entender cómo se realizan estos cálculos es parte de la necesaria comprensión de las prácticas financieras en las que las mujeres desempeñan un papel fundamental.

\section{Los estragos de la pandemia}

La pandemia ha venido a dificultar aún más el proceso ya de por sí difícil de las mujeres, como se puede ver en los casos de Teresa, Andrea y Dorian. Teresa ha trabajado para el gobierno de Estados Unidos cuidando a una señora de la tercera edad. Sin embargo, le pareció muy pesado continuar con el trabajo y renunció, ya que tenía que ir con ella también los fines de semana y, precisamente, esos días eran en los que sentía más compromiso de atender a su familia. De entonces a la fecha realiza diversas actividades 
para ganar dinero a la vez que tiene más control de sus horarios. Por ejemplo, vende productos de belleza, organiza ventas de garaje, e incluso ha apoyado a sus amigas en la limpieza de sus casas tanto del lado mexicano como del estadounidense. Todas estas actividades le permiten tener al día sus tarjetas de crédito y realizar algunas compras para ella y sus hijos adolescentes. También se dedicó a realizar estudios para el GED $^{5}$ en inglés y para el examen de la ciudadanía. Sin embargo, ninguna de estas actividades le da créditos para su jubilación.

El esposo de Teresa se contagió de COVID-19 en fechas recientes y también contagió a su hija. Ella estuvo al cuidado de ambos en su casa en el Valle Imperial durante el periodo de aislamiento y, justo cuando se recuperaron, su hermano menor, quien vive solo en Mexicali, dio positivo y se fue a cuidarlo. A los días ella también dio positivo y permaneció aislada junto con su hermano en Mexicali hasta que recobro su salud. Se estuvieron tratando en esta ciudad con una doctora que estuvo administrándoles un tratamiento. Afortunadamente ni ella ni su hermano padecen comorbilidad, y pronto salieron adelante.

Por otro lado, Andrea tuvo que interrumpir sus estudios de enfermería al nacer su primera hija, hace poco más de 20 años. Lamenta que hasta la fecha no ha podido retornar a la escuela, y quizá ya no lo haga. Dice que no puede parar de trabajar. Estuvo por casi siete años sin laborar por un salario, pues en ese tiempo su esposo se hacía cargo de mantener a la familia y ella se encargaba principalmente de las labores domésticas como preparación de alimentos, cuidados y limpieza de la casa. Recientemente se separó de su esposo, lo que la orilló a regresar al trabajo. Ella participa en una agencia especializada en el cuidado de personas en el Valle Imperial. Dice que batalló mucho para entrar en esa compañía, y a la vez le sorprende que sea difícil ingresar a ella ya que es una actividad muy mal pagada. Cree que la gente tiene interés en llegar a ese centro de trabajo debido a la flexibilidad en el horario. Y eso es lo que buscan muchas mujeres, tener flexibilidad en el horario de trabajo para conciliarlo con la familia. Dice que si se presenta un compromiso o algo inesperado se puede llamar a la oficina para que la reemplacen, pero tiene que ser a principio de mes, para que no le genere un mal historial.

Comenta que a veces hay casos más sencillos que otros, o de menos desgaste, como cuando la gente que cuida todavía se puede valer por sí misma, es decir, se cambia, se baña, se cocina y a veces simplemente quiere compañía, pero en otras ocasiones es todo lo contrario. Por ejemplo, explica que hay gente postrada que pesa mucho, y eso dificulta los cuidados, pero piensa que el principal problema con este trabajo es lo mal pagado que está, además de tener que dejar a sus hijos solos todo el día en el departamento, mientras otras personas han gozado de un cheque de desempleo.

A pesar de que es alto el costo de dejar a sus hijos solos en el departamento, dice que si no fuera por la pandemia estarían en la escuela y no en casa tomando clases en línea, por lo tanto, no podría aprovechar esta buena racha de trabajar doce horas por día (antes no le habían ofrecido tantas horas de trabajo) pues no tiene quien los recoja de la escuela; sin embargo, dice que la buena racha pronto se acabará: hace unos días las amenazaron en el trabajo con recortarles próximamente $30 \%$ de la cantidad de horas.

${ }^{5}$ El GED o General Educational Development Test es el examen de desarrollo de educación general y es una certificación para el estudiante que haya cumplido con los créditos necesarios del nivel de escuela preparatoria estadounidense o canadiense. 
Andrea también compartió que su hermana que vive en Mexicali se enfermó de COVID-19, lamentó mucho no poder apoyarla debido a su trabajo, a sus compromisos familiares y al temor de contagiarse. Sin embargo, estuvo en comunicación con ella vía telefónica, por medio de WhatsApp.

Y como muchas mujeres, Dorian, quien vive en Estados Unidos, pero tiene su casa en Mexicali, debe trabajar para sostener a su familia, la mayor parte ya está en Estados Unidos y del lado mexicano tiene unas hermanas. Lleva varios años como cajera en una cadena comercial muy conocida en Caléxico, pero se dio cuenta que la compañía no estaba dándole la seriedad debida a la pandemia al no implementar desde un principio protocolos para protegerlos debidamente. Hasta cierto punto se siente respaldada porque la compañía le brinda buenas prestaciones, por ejemplo, el servicio médico. Sin embargo, dice, el riesgo está ahí. Recientemente se tomó unas vacaciones ya que estaba muy presionada, y menciona que ya son tres personas del trabajo que fallecen por COVID-19. Cuenta que en sus vacaciones fue a Mexicali, pues hacía varios meses que no cruzaba.

Andrea y Teresa, al contar con documentos para permanecer en Estados Unidos, no tienen problema de movilidad geográfica, ellas pueden ir a México y regresar a Estados Unidos sin grandes complicaciones, sin embargo, como se ve, no escapan de las condicionantes de género y son quienes se hacen cargo de los cuidados de los demás, aún a costa de su salud.

Asimismo, de alguna manera se puede hablar de violencia económica cuando mujeres como Dorian se ven obligadas a seguir laborando bajo condiciones riesgosas, como Andrea, quien recibe un pago muy inferior por su trabajo, o como Teresa, quien tiene que hacer malabarismos para poder pagar sus deudas. Y difícilmente se puede desvincular la exclusión, discriminación y violencia económica que sufren las mujeres de la violencia social y cultural. El caso de las mujeres violentadas en tanto son responsables del cuidado, de la economía y de la salud de la familia es una historia que se repite una y otra vez. Los impedimentos para trabajar fuera del hogar, la necesidad de asumir la responsabilidad de los hijos, y las agresiones a su integridad física inciden en las posibilidades de agenciarse seguridad económica y bienestar. El hostigamiento también está presente en las llamadas "fuerzas del mercado". Estas son complejas e involucran una gama de normatividades, recurren a tecnologías sofisticadas y se nutren de información cada vez más especializada, pero en última instancia están conformadas por relaciones entre personas, grupos e instituciones mediadas por representaciones, estimaciones y proyecciones de valor, en los cuales intervienen factores de nacionalidad, estatus legal, clase y género.

La seguridad económica, los cuidados no remunerados y la violencia hacia las mujeres, son factores que influyen en el mal manejo comunitario de la pandemia. En la zona transfronteriza esta problemática adquiere gran relevancia. Se ha descuidado la protección de las familias y en particular de las mujeres y las relaciones de género.

Aunque se percibe una ligera recuperación económica desde junio, los hombres están regresando al mercado laboral más rápido que las mujeres, y muchas de ellas lo están haciendo a empleos en condiciones desventajosas, en parte por la carga desproporcionada que tienen dentro del hogar. $53 \%$ de las mujeres trabajadoras se concentra en sectores que han sido más afectados por la pandemia y cuya recuperación podría ser más lenta. Entre estos sectores se encuentran hospedaje y alimentos, comercio al por menor y otros servicios; 
las mujeres se encuentran subrepresentadas en los puestos de liderazgo, tanto en el sector público como en el privado. Esto reduce la posibilidad de que las necesidades de las mujeres se vean reflejadas en la toma de decisiones. (Avendaño et al., 2020)

De abril a julio de 2020, las trabajadoras por cuenta propia aumentaron de $14 \%$ a 23\%, mientras que la tasa de las trabajadoras no remuneradas se duplicó (Encuesta Telefónica de Ocupación y Empleo [ETOE] en Alavez, 2020). Este problema representa un retroceso de 10 años en la lucha por la equidad de género, aseguró Mía Perdomo, primera ejecutiva de Aequales, empresa especializada en reducir las brechas de género en el ambiente laboral (Alavez, 2020).

Y como se puede ver en los casos presentados, es común que las mujeres sean violentadas, que se les remunere un salario más bajo que a los hombres y que sean ellas las responsables de sacar adelante a la familia, tanto en términos económicos como en salud. Como se ha explicado, con la pandemia se incrementaron las desigualdades en términos de ingreso, se aumentaron las responsabilidades en torno a la salud de la familia, y la mayoría es responsable de seguir la educación en línea con sus hijos.

Es importante mencionar que

las pandemias y los brotes tienen efectos diferenciales en las mujeres y los hombres. Desde el riesgo de exposición y la sensibilidad biológica a la infección hasta las consecuencias sociales y económicas, es probable que las experiencias de las personas varíen según sus características biológicas y de género y su interacción con otros determinantes sociales. Por ello, los planes estratégicos mundiales y nacionales de preparación y respuesta frente al COVID-19 deben basarse en un análisis sólido de género y garantizar una participación significativa de los grupos afectados, incluidas las mujeres y las niñas, en la adopción y ejecución de las decisiones. (Organización Mundial de la Salud, 2020)

\section{Conclusiones}

La pandemia ha sido fuente de preocupación desde muchos ángulos, desde el incremento cotidiano de muertes, hasta la economía. Pero también lo es por lo que ha significado en términos de las relaciones de género. Como se ha descrito arriba, con la pandemia se incrementó significativamente el trabajo de la mujer: los cuidados, no solo de sí mismas y sus familias nucleares, sino de parientes más lejanos. La doble jornada, que incluye trabajo en casa y trabajo remunerado fuera del hogar, se convierte en triple jornada, al incrementarse su rol como cuidadora. $Y$ se agrega a esta una cuarta jornada, no menos pesada, la de maestra en este contexto de pandemia. $\mathrm{Al}$ respecto, Lewis (2020), en su análisis, estima que el coronavirus es un desastre para el feminismo y se pregunta y se responde ¿qué necesitan los pacientes pandémicos? Cuidado. ¿Qué necesitan las personas mayores que se aíslan a sí mismas? Cuidado. ¿Qué necesitan los niños que se quedan en casa y no van a la escuela? Cuidado. Todo este cuidado, este trabajo de cuidado no remunerado, recaerá más sobre las mujeres.

Las mujeres ya de por sí llevaban las riendas de su hogar, al encargarse de la nutrición, bienestar y salud de su familia. Todas lo han naturalizado como parte de sus obligaciones como mujeres. La desigualdad de género ha ido en aumento. 
La seguridad económica es de suma importancia. Aquí hay que hacer notar la diferenciación en el empleo y la retribución económica que por ello reciben. Las mujeres empleadas en los circuitos agrícolas, las "corridas", tienden a ser relegadas a los trabajos más difíciles y peor pagados. El acceso a empleos bien remunerados se ve restringido por las atribuciones de género: la desvalorización de la mujer y sus capacidades, la falta de información dadas las limitaciones de redes sociales y de tiempo, y el que las mujeres se ven obligadas a tomarse a cuestas la responsabilidad del hogar, de los enfermos y los hijos, de su manutención, su salud y su educación.

Y, por otro lado, mujeres que llevaban procesos legales en defensa de sus derechos y los derechos de sus hijos se ven imposibilitadas de proseguir la lucha por el cierre de la frontera. Si bien en general estas tienden a haber logrado un avance en su proceso de autonomía y empoderamiento, este se ve amenazado con el cierre de la frontera con todas sus implicaciones.

Como se puede ver, la pandemia, y en particular las restricciones en torno a ella, develan de manera explícita y clara las maneras en que se ha naturalizado el papel de la mujer como cuidadora, la resignación en la obtención de bajos salarios y, en general, la desigualdad, además de que las recomendaciones de la onu de centrar la atención en las dimensiones de género no han tenido eco en esta región.

Ante la falta de una política que contemple las dimensiones de género, el gran riesgo, como bien se menciona en el estudio del COVID-19 Global Response Tracker, es que se retroceda de manera importante en los logros que se habían obtenido en la equidad de género.

\section{Agradecimientos}

Las autoras agradecen a Diana Lizheth Mendoza Rivera, estudiante de la carrera de administración pública de la Universidad Autónoma de Baja California por su asistencia en esta investigación.

\section{Referencias}

Alavez, M. (2020, 28 de septiembre). El virus aumentó la brecha de género laboral. El Sol de San Luis. https://www.elsoldesanluis.com.mx/mexico/sociedad/ evolucion-el-virus-aumento-la-brecha-de-genero-laboral-equidad-genero-pandemia-coronavirus-covid-19-imco-campo-laboral-5816368.html

Avendaño, M., Cortés, P., Masse, F. \& Paredes, R. (2020, 14 de septiembre). Diagnóstico IMCO: Mujer en la economía pos-covid. Instituto Mexicano para la Competitividad, A. C. https://imco.org.mx/wp-content/uploads/2020/09/14092020_Mujeren-la-economi\%CC\%81a-pos-covid_Documento.pdf

Baja California: instauran sistema de reconocimiento facial en Garita de Caléxico. Autoridades norteamericanas instalaron tecnología de comparación biométrica y facial en el cruce con Mexicali. (2021, 18 de febrero). El Heraldo de México. https://heraldodemexico.com.mx/nacional/2021/2/18/bajacalifornia-instauran-sistema-de-reconocimiento-facial-en-garita-de-calexico-259730.html 
Campos, A. \& Odgers, O. (2012). Crossing the border: mobility as a resource in the Tijuana/San Diego and Tecún Umán/Tapachula regions. Estudios Fronterizos, 13(26), 9-32. https://doi.org/10.21670/ref.2012.26.a01

Chant, S. (2003). Female household headship and the feminisation of poverty: facts, fictions and forward strategies. New Working Paper Series (9). https://www.lse.ac.uk/gender/assets/documents/research/working-papers/Female-Household-Headship-and-the-Feminisation-of-Poverty.pdf

Cierre de frontera México-EU por COVID-19, decisión política, no sanitaria: WSJ. (2020, 3 de octubre). Forbes. https://www.forbes.com.mx/noticias-cierre-frontera-mexico-eu-covid-19-decision-politica-no-sanitaria-wsj/

Coronavirus: la Corte Suprema de EE.UU. suspendió sus actividades por primera vez en más de un siglo. (2020, 16 de marzo). Infobae. https://www.infobae.com/america/ eeuu/2020/03/16/coronavirus-la-corte-suprema-de-eeuu-suspendio-sus-actividades-por-primera-vez-en-mas-de-un-siglo/

COVID-19 Global Gender Response Tracker. (2020). UNWOMEN-UNDP. https://data. undp.org/gendertracker/

COVID-19 ocasiona impactos "devastadores" en las mujeres, afirma la directora de la oPs. (2021, 26 de mayo). ops/oms. https://www.paho.org/es/noticias/26-5-2021-covid-19-ocasiona-impactos-devastadores-mujeres-afirma-directora-ops

Enríquez, R. (1998). Pobreza y hogares de jefatura femenina en México. En R. Gallardo \& J. Osorio (Coords.), Los rostros de la pobreza: el debate. Tomo II. (pp. 251-297). Iteso/Universidad Iberoamericana.

Folbre, N. (1982). Exploitation comes home: a critique of the Marxian theory of family labour. Cambridge Journal of Economics, 6(4), 317-329.

Forbes Staff. (2021, 11 de julio). México reporta 62 nuevas muertes y suma 234969 decesos por COVID-19. Forbes. https://www.forbes.com.mx/mexico-reporta-62-nuevasmuertes-y-suma-234969-decesos-por-covid-19/

García, N. \& Niño, L. (2011, 6-11 de septiembre). Migración femenina, trabajo doméstico remunerado y capital social en Mexicali, Baja California [ponencia]. XXVIII Congreso de la Asociación Latinoamericana de Sociología (aLAs). Recife, Brasil.

Gibson-Graham, J. K. (1996). The end of capitalism (as we knew it). A femenist critique of political economy. Blackwell.

Gomez, M. (2020, 10 de junio). En los campos de California, los hacinados trabajadores agrícolas propagan el coronavirus. Los Angeles Times. https://www.latimes.com/espanol/california/articulo/2020-06-10/en-los-campos-de-california-los-hacinados-trabajadores-agricolas-propagan-el-coronavirus

Harris, O. (1981). Households as natural units. En K. Young, C. Wolkowitz \& R. McCullagh (Eds), Of marriage and the market: women's subordination in international perspective. CSE Books.

Lara-Valencia, F. \& García-Pérez, H. (2021). Las fronteras de la pandemia: lecciones para la gobernanza y la cooperación en las ciudades de la frontera México-Estados Unidos. Estudios Fronterizos, 22. https://doi.org/10.21670/ref.2104067

Lewis, H. (2020, 19 de marzo). The coronavirus is a disaster for feminism. Pandemics affect men and women differently. The Atlantic. https://www.theatlantic.com/international/archive/2020/03/feminism-womens-rights-coronavirus-covid19/608302/ 
López, S. (1994). Mujeres y redes familiares en la producción social de los hogares transfronterizos. En N. Ojeda \& S. López (Coords.), Familias transfronterizas en Tijuana: dos estudios complementarios (pp. 51-74, Serie Cuadernos 6). El Colegio de la Frontera Norte.

López, S. (2020). Cuidado a través de la frontera: trayectorias transfronterizas de cuidados en la región Tijuana-San Diego. Estudios Fronterizos, 21. https://doi. org/10.21670/ref.2002044

Meza, A. (1989). Educación y migración en la frontera Mexicali-Caléxico. Estudios Fronterizos, 8(18-19), 136-147. https://doi.org/10.21670/ref.1989.18-19.a08

Moore, H. (1988). Feminism and Anthropology. Polity Press/Blackwell Publishers Ltd.

Mujeres, género, violencia, pandemia y políticas públicas. (2020, 11 de octubre). Diario Jornada. https://jornadaonline.com/mujeres-genero-violencia-pandemia-y -politicas-publicas/

Niño, L. \& Villarreal, M. (2013a). Flujos transfronterizos: intercambios y transacciones. El caso de las mujeres mexicanas que se trasladan cotidianamente en la frontera entre Mexicali y Caléxico. En G. Macías \& L. Parada (Coords.), Mujeres, su participación económica en la sociedad (pp. 149-166). Editorial Universitaria Libros que transforman-Universidad de Guadalajara. http://repositorio.cualtos.udg. mx:8080/jspui/bitstream/123456789/792/1/Mujeres\%2C\%20su\%20participaci\%C3\%B3n\%20econ\%C3\%B3mica\%20en\%20la\%20sociedad.pdf

Niño, L. \& Villarreal, M. (2013b). Prácticas sociales de mujeres transfronterizas: el caso de Mexicali-Caléxico. Instituto de Investigaciones Sociales-Universidad Autónoma de Baja California.

Niño, L., Villarreal, M. \& Arriaga R. (2012). Quoras, pesos y dólares: flujos de divisas y finanzas en el caso de mujeres transmigrantes de Mexicali-Caléxico y sus valles. Instituto de Investigaciones Sociales-Universidad Autónoma de Baja California.

Ojeda, N. (1994). Familias transfronterizas en Tijuana: Migración y trabajo internacional. En N. Ojeda \& S. López (Coords.), Familias transfronterizas en Tijuana: dos estudios complementarios (pp. 9-49, Serie Cuadernos 6). El Colegio de la Frontera Norte.

Organización Mundial de la Salud. (2020, 14 de mayo). El género y la Covid-19. https:/ / apps.who.int/iris/bitstream/handle/10665/332242/WHO-2019-nCoV-Advocacy_brief-Gender-2020.1-spa.pdf?isAllowed=y\&sequence $=1$

Orraca, P. (2019). Cross-border earnings of Mexican workers across the US-México border. Journal of Borderlands Studies, 34(3), 451-469. https://doi.org/10.1080/ 08865655.2017 .1294025

Registran hasta 8 horas de espera en Garita Centro. (2020, 24 de agosto). Adelante Valle. https://www.ivpressonline.com/adelantevalle/registran-hasta-8-horas-de-espera-en-garita-centro/article_6df9e768-e5d0-11ea-ad6a-7744075b3f85.html

Rocha, D. \& Orraca, P. (2018). Estudiantes de educación superior transfronterizos: residir en México y estudiar en Estados Unidos. Frontera Norte, 30(59), 103-128. https://doi.org/10.17428/rfn.v30i59.880

Roldán, M. (1988). Renegotiating the marital contract: Intrahousehold patterns of money allocation and women's subordination among domestic outworkers in Mexico City. En D. Dwyer \& J. Bruce (Eds.), A home divided, women and income in the third world (pp. 229-247). Stanford University Press. 
Ruíz, M. (2021). Las estadísticas sanitarias y la invisibilidad por sexo y género durante la epidemia de COVID-19. Gaceta Sanitaria, 35(1), 95-98. https:// www.gacetasanitaria.org/es-las-estadisticas-sanitarias-invisibilidad-por-articulo-S0213911120300911

Sández, A., Niño, L., García, N. \& Montoya, G. (2016). Perfil económico y laboral de la transmigración femenina México-Estados Unidos en actividades agrícolas. El caso del Valle Imperial, California. En J. Moreno, C. Valencia \& L. Niño (Coords.), Estudios fronterizos: nuevos escenarios de la migración (pp. 287-297). UABC/ Fundación Konrand Adenauer Stiftung.

Vargas, E. \& Coubès, M. (2017). Working and giving birth in the United States: Changing strategies of transborder life in the North of Mexico. Frontera Norte, 29(57). https://fronteranorte.colef.mx/index.php/fronteranorte/article/ view/912/1300

Villarreal, M. (2007). La economía desde una perspectiva de género: de omisiones, inexactitudes y preguntas sin responder en el análisis de la pobreza. La Ventana, revista de estudios de género, 3(25), 7-42. http://www.scielo.org.mx/scielo. php?script=sci_arttext\&pid=S1405-94362007000100007

Villarreal, M. (2017). Violencia de género. Notas para un marco conceptual. En L. Niño, P. González, M. Barajas \& S. Figueroa (Coords.), Estudios de género en el norte de México. En las fronteras de la violencia (pp. 35-64). UABC. https:// www.academia.edu/34933947/ESTUDIOS_DE_G\%C3\%89NERO_EN_EL_ NORTE_DE_M\%C3\%89XICO_EN_LAS_FRONTERAS_DE_LA_VIOLENCIA

Villarreal, M., Greene, J. \& Niño, L. (2015). Juggling Currencies in Transborder Contexts: Mexico/Us. Institute for Money, Technology and Financial Inclusion-UCI School Social Sciences. https://www.imtfi.uci.edu/villareal.php

Villarreal, M. \& Niño, L. (2016). Financial practices on "the Borderlands" (La Línea) in times of crisis. Human Organization, 75(2), 151-158. https://doi. org/10.17730/0018-7259-75.2.151

Magdalena Villarreal Martínez

Mexicana. Doctora cum laude en antropología por la Universidad de Wageningen, Holanda (1994). Es profesora-investigadora en ciesas, Occidente. Pertenece a la Academia Mexicana de Ciencias (AMC) y es nivel III en el Sistema Nacional de Investigadores (SNI). Dirige el seminario internacional sobre el estudio social del dinero, la economía y las finanzas desde una perspectiva antropológica en coordinación con el Institute for Money, Technology and Financial Inclusion de la Universidad de California. Líneas de investigación: estudio social del dinero y finanzas, pobreza, migración y género. Publicación reciente: Villarreal, M. \& Greene, J. (2020). Juggling currencies in transborder conetxs. Oxford Research Encyclopedias of Anthropology. https:/ / doi.org/10.1093/acrefore/9780190854584.013.207 


\begin{abstract}
Lya Margarita Niño Contreras
Mexicana. Doctora en ciencias sociales por el Programa UAS-UABC-CIAD-Unison, 2005. Investigadora en el Instituto de Investigaciones Sociales de la Universidad Autónoma de Baja California. Pertenece al sNi desde 2007. Líder del Cuerpo Académico Estudios Sociales. Líneas de investigación: migración étnica, poder y empoderamiento, así como finanzas de mujeres en contextos transfronterizos. Publicación reciente: Villarreal, M. \& Niño, L. (2020). Una mujer indígena comprometida con la justicia, la igualdad y los derechos de las jornaleras. En R. Rojas, A. González \& E. Marúm (Coords.), Construyendo espacios de igualdad: liderazgos y participación social y política de las mujeres (pp. 123-138). Universidad de Guadalajara/unEsco.
\end{abstract}

